\title{
GCU
}

Glasgow Caledonian

University

University for the Common Good

\section{Estimating sign-dependent societal preferences for quality of life}

Attemaa, Arthur E.; Brouwer, Werner B.F.; I'Haridon, Olivier; Pinto, Jose Luis

Published in:

Journal of Health Economics

DOI:

10.1016/j.jhealeco.2015.07.006

Publication date:

2015

Document Version

Author accepted manuscript

Link to publication in ResearchOnline

Citation for published version (Harvard):

Attemaa, AE, Brouwer, WBF, l'Haridon, O \& Pinto, JL 2015, 'Estimating sign-dependent societal preferences for quality of life', Journal of Health Economics, vol. 43, pp. 229-243. https://doi.org/10.1016/j.jhealeco.2015.07.006

\section{General rights}

Copyright and moral rights for the publications made accessible in the public portal are retained by the authors and/or other copyright owners and it is a condition of accessing publications that users recognise and abide by the legal requirements associated with these rights.

Take down policy

If you believe that this document breaches copyright please view our takedown policy at https://edshare.gcu.ac.uk/id/eprint/5179 for details of how to contact us. 


\title{
Estimating sign-dependent societal preferences for quality
}

\section{of life ${ }^{1}$}

Arthur E. Attema ${ }^{\mathrm{a}}$, Werner B.F. Brouwer ${ }^{\mathrm{b}}$, Olivier l'Haridon ${ }^{\mathrm{c}}$, Jose Luis Pinto ${ }^{\mathrm{d}}$

\author{
a (Corresponding author) iBMG, Erasmus University, P.O. Box 1738, 3000 DR Rotterdam, the \\ Netherlands. E-mail: attema@bmg.eur.nl, --31-10.408.91.29 (O); --31-10.408.90.81 (F) \\ ${ }^{\mathrm{b}}$ iBMG, Erasmus University, The Netherlands \\ ${ }^{\mathrm{c}}$ CREM, Université de Rennes, France \\ ${ }^{\mathrm{d}}$ Yunus Centre, Glasgow Caledonian University, UK.
}

July, 2015

ABSTRACT. This paper is the first to apply prospect theory to societal health-related decision making. In particular, we allow for utility curvature, equity weighting, sign-dependence, and loss aversion in choices concerning quality of life of other people. We find substantial inequity aversion, both for gains and losses, which can be attributed to both diminishing marginal utility and differential weighting of better-off and worse-off. There are also clear framing effects, which violate expected utility. Moreover, we observe loss aversion, indicating that subjects give more weight to one group's loss than another group's gain of the same absolute magnitude. We also elicited some information on the effect of the age of the studied group. The amount of inequity aversion is to some extent influenced by the age of the considered patients. In particular, more inequity aversion is observed for gains of older people than gains of younger people.

Key Words: equity weighting, loss aversion, prospect theory, QALYs

JEL CLASSIFICATION: D63, I10

\footnotetext{
${ }^{1}$ This research was made possible through a grant from The Netherlands Organization for Health Research and Development (ZonMW), project number 152002041. We are grateful to Peter P. Wakker for advice and Job van Exel for assistance in the design of the experiment. The usual disclaimer applies.
} 


\section{Introduction}

Cost-effectiveness analyses are increasingly being used in health care policy in order to guide the allocation of health care resources. The concept of Quality Adjusted Life Years (QALYs) is an important tool to quantify the effects in these analyses. The major purpose of costeffectiveness analyses is to obtain the highest health gains with a given budget. However, it is by now well-known that many individuals have a preference for the distribution of health gains alongside their magnitude (Dolan et al., 2005). In particular, people tend to give different weights to the same health improvements depending on severity (i.e., initial health status (Nord et al., 1999)), age (Johannesson and Johansson, 1997), lifetime health (Williams, 1997), and distribution among the population (Cuadras-Morató et al., 2001; Dolan and Tsuchiya, 2011; Johannesson and Gerdtham, 1996; Lindholm and Rosén, 1998). These preferences reflect a trade-off between efficiency (defined as maximising health) and some other factor, which is likely to include equity considerations. Equity weighting is very important for societal decisions and can have enormous ethical consequences. This highlights the need for incorporating equity weighting into health-related decision making, and to obtain proper empirical estimations of these weights.

Health-related social welfare functions (HRSWFs) have been proposed as a way to model this trade-off (Dolan, 1998; Wagstaff, 1991). A few different measurement methods have been proposed recently to elicit the HRSWF's parameters. Dolan (1998) performed a small pilot study asking students to compare two individuals at different starting health states (valued on a 0-1 scale) and assumed the power family underlying the HRSWF. He reported the Cobb-Douglas log-linear function to best represent the answers. Because of his use of different initial health states, the obtained equity weights can be viewed to relate to the severity argument (see Nord et al, 1999). Dolan and Robinson (2001) studied trade-offs between treatments that give different gains to different individuals with the same initial health status and found inequity neutrality. Johannesson and Gerdtham (1996) and Andersson and Lyttkens (1999) used a veil of ignorance approach for this purpose. Andersson and Lyttkens (1999) reported a median marginal trade-off varying from 0.11 to 0.35 years of life expectancy among the worst off in exchange for 1 year lost among the best off in society, whereas this median was 0.45 in Johannesson and Gerdtham (1996). Abásolo and Tsuchiya $(2004 ; 2013)$ even found that people sometimes violate monotonicity in order to achieve a more equitable distribution; i.e., they sometimes prefer an outcome where all beneficiaries receive less but with a smaller difference between them. 
Little research has been performed on equity weighting functions in the health domain. Bleichrodt (1997) suggested the extension of rank-dependent utility theory from decision under risk to social decision making, by giving different weights to different individuals or outcomes, in a similar fashion as assigning decision weights to probabilities in decisions under risk. Subsequently, Bleichrodt et al. (2004) pointed out that it may be unnecessarily restrictive to model aversion to health inequality solely through a concave utility function, and showed that the rank-dependent approach is consistent with the most popular HRSWFs, including those used by Dolan (1998). Bleichrodt et al. (2005) were the first to apply this rank-dependent approach empirically by implementing an adaptation of the trade-off method (Wakker and Deneffe, 1996). They elicited the equity weighting function for QALYs and reported inequity aversion, but they only considered gains. Subsequently, Turpcu (2013) extended Bleichrodt et al.'s (2005) approach to the loss domain, but did not elicit a loss aversion index. For gains, he found inequity neutrality for low proportions and inequity aversion for medium to large proportions. In the loss domain, there was inequity neutrality for all proportions.

The disadvantage of the approaches used by Bleichrodt et al. (2005) and Turpcu (2013) is that they are quite labour intensive, requiring several steps to elicit equity weights. Unlike Turpcu (2013), who used a student sample, and Bleichrodt et al. (2005) who used both a student sample and a representative sample but of a small size, we use a large sample that is representative of the general public above 18 years. This is necessary if one aims to derive policy recommendations from research. However, it is true that internet panels also have some limitations since respondents might be different from a random sample of the general population in unobserved ways. Even in this case it seems that they should reflect societal preferences better than students. Moreover, Schwappach and Strasmann (2006) reported encouraging results regarding the reliability of internet panels in a stated preference elicitation task to measure preferences for resource allocation in health care.

Using an approach as labour intensive as these previous studies would be prohibitively expensive when applied to a large general public sample. Therefore, we implement a simpler and shorter method. Another objective of this study is to extend the work of Bleichrodt et al. (2005) and Turpcu (2013) to include the estimation of loss aversion in this context.

Another interesting question to pursue is whether equity weighting, utility curvature, and loss aversion differ when the age of the group under consideration is varied. One reason why we might expect this is because reference points for health may vary with age. In 
general, health deteriorates with age, so individuals may have diminishing expectations of the (average, normal or acceptable) health level of older people than that of younger people (Brouwer and van Exel, 2005; Brouwer et al., 2005). These lower expectations may translate into lower reference points for the elderly. In turn, downwardly shifting reference points may cause health levels that are perceived as losses for young people to become gains for elderly people. Furthermore, we know from prospect theory (PT) that losses are generally treated differently than gains, with losses getting more weight than gains, and possibly different shapes of the utility functions for gains and losses and the equity weighting functions in both domains. Hence, even if individuals have the same utility and equity weighting functions for different age groups, an age-dependent reference point may result in different preferences for older people than for younger people because of a gain-loss asymmetry. The amount of loss aversion may likewise also be age-dependent.

First, we predict a particular quality of life $(\mathrm{QoL})$ level to be more likely to be regarded as a loss for young people than for old. Because of loss aversion, this would imply people attach more importance to improving health for the young than to improving health of the old, since the improvement would be a reduction of a loss for the young but an extension of a gain for the old. For example, if someone considers the reference point for an 80-year old to be $30 \%$ and for a 50 -year old to be $90 \%$, then an increase in QoL from $60 \%$ to $70 \%$ will be an extension of a gain for the 80 -year old, but a reduction of a loss for the 50 -year old. The $10 \%$-point increase will then get a higher weight for the 50 -year old because it is multiplied by a loss aversion parameter larger than 1 . Second, if the utility and/or the equity weighting functions differ between gains and losses, a further difference in preferences for the separate age groups may emerge. For instance, individuals may be inequity seeking for a given prospect when it involves a young group, but nevertheless inequity averse for that same prospect when it involves an old group. A reason for such a difference is that people may be inequity seeking for losses and inequity averse for gains, in a similar fashion as is commonly found for monetary outcomes in a risk context (Kahneman and Tversky, 1979). There is no evidence yet to predict the effect of the utility/equity weighting difference on the differential preferences for young and old.

This research is the first to simultaneously elicit societal utility and equity weighting for both gains and losses, together with a loss aversion index in the QoL domain. In addition, our research involves another difference to previous elicitations of the HRSWF. Our experiment estimates people's societal utility function over QoL for a group of people of the same age, alongside the relative weight they give to the better-off part of this group, and does 
so for different groups, each of a different age. This allows us to test whether individuals have age-dependent societal preferences for health, which need not be the same as the earlier reported discrimination according to age (Johannesson and Johansson, 1997). For instance, people may prefer to give 1 QALY to a 30-year old person than to a 70-year person because they think the younger deserves it more or is more productive (age discrimination), and, therefore, attach more weight to a QALY gained by the 30-year old person. However, at the same time, they may also have a societal utility function that is more concave for the older one, and they may consider the gained QALY an augmentation of a gain for the 70-year old, but a reduction of a loss for the 30-year old, because the reference point is generally higher for young people than for older people. The QALY gain will then get a higher weight for the 30 -year old because it is multiplied by a loss aversion parameter larger than 1 . In sum, we present research that is methodologically innovative and also broadens knowledge.

We find substantial inequity aversion ${ }^{2}$, both for gains and for losses. This can be explained by a concave utility function as well as by equity weighting of proportions. We also observe substantial loss aversion: losses for one part of the group loom larger than gains for another part. Some significant differences between different age groups are found, and the arguments provided by the subjects support the intuition attached to the parameters estimated on their responses to the allocation task.

The remainder of this paper is organized in the following way. Section 2 presents our model and introduces notation, Section 3 describes the experimental design, Section 4 gives the results and Section 5 provides a discussion and conclusion.

\section{Method}

\subsection{Notation}

We consider a population of $\mathrm{n}$ individuals of age $\mathrm{L}$ and let $\left(\mathrm{q}_{1}, \ldots, \mathrm{q}_{\mathrm{n}}\right)$ denote the QoL profile, giving QoL score q to individual i. Following Bleichrodt et al. (2005), we assume QoL profiles are rank-ordered with $\mathrm{q}_{1}>\ldots>\mathrm{q}_{\mathrm{n}}$, unless stated otherwise.

\footnotetext{
${ }^{2}$ Sometimes this behavior is termed 'equity seeking', but we prefer 'inequity aversion' to facilitate the comparison with its counterpart for individual decision making under risk ('risk aversion').
} 


\subsection{The PT-QALY model}

If we want to quantify the equity-efficiency trade-off, we have to obtain estimations of the parameters of the HRSWF. The general HRSWF may be written as $\mathrm{W}=\mathrm{f}\left(\mathrm{q}_{1}, \ldots, \mathrm{q}_{\mathrm{n}}\right)$. One frequently studied specification is the isoelastic function proposed by Wagstaff (1991). Dolan (1998) applied a two-individual variant of this function:

$\mathrm{W}=\ln \left(\mathrm{q}_{1}\right)+B \ln \left(\mathrm{q}_{2}\right)$.

Dolan (1998) then continues with discussing a special case of this function, the CobbDouglas function which is analogous to Eq.1.

In this paper, we employ the rank-dependent QALY model (Bleichrodt et al., 2004) and extend it to account for sign-dependence. We adopt two separate social utility functions, one for gains and one for losses, two separate equity weighting functions, and include loss aversion. Moreover, we extend the rank-dependent QALY model to allow for nonlinear utility, as was also done by Bleichrodt et al. (2005). We thus end up with a social version of the individual QALY model under PT (Bleichrodt and Miyamoto, 2003). We assume that the HRSWF represents the social value of the QoL profile $\left(q_{1}, \ldots, q_{n}\right)$ by:

$\mathrm{W}=\sum_{\mathrm{i}=1}^{\mathrm{n}} \pi_{\mathrm{i}} \mathrm{U}\left(\mathrm{q}_{\mathrm{i}}\right)$

where the $\pi_{i}$ are equity weights, defined as $\pi_{i}=\omega\left(\frac{i}{n}\right)-\omega\left(\frac{i-1}{n}\right)$. The function $\omega$ is a nondecreasing function defined over $[0,1]$, with $\omega(0)=0$ and $\omega(1)=1$.

The Cobb-Douglas function is compatible with the rank-dependent utility representation (Eq. 2) if $\mathrm{U}(\mathrm{q})$ is logarithmic (Bleichrodt et al., 2004), with B conceptually similar to $\pi_{\mathrm{i}}$. In this paper, we elicit more general utility functions (power functions) and also perform a new test of the Cobb-Douglas HRSWF. ${ }^{3}$ Our model is more general than the Cobb-Douglas model of Dolan (1998), in that it allows for other parametric specifications for the individual utility functions than only power (e.g. exponential utility). Moreover, our model is more powerful than Eq. 1, because our weight parameter $\pi_{\mathrm{i}}$ is much less restricted

\footnotetext{
${ }^{3}$ Bleichrodt et al. (2005) found little evidence supporting it, but our study investigates it in a different setting and extends the test to the utility function for losses.
} 
than B. Our model also allows for more than two arguments, although in this study we use only two arguments for convenience.

In the HRSWF, the $\pi_{\mathrm{i}}$ 's have a similar interpretation as in Bleichrodt et al. (2005): they represent the equity weights attached to the proportion of the group obtaining the best [worst] outcome in the gains [losses] scenario. As explained by Bleichrodt et al. (2005, p.657), if $\omega$ is convex, then the policy maker is averse to inequalities, in the sense that he will always prefer a transfer of QoL from a group that has relatively high QoL to a group that has less, as long as the rank-ordering of the groups in terms of the QoL obtained is not affected. A weight lower than the amount of the proportion implies inequity aversion for gains, since the better-off receive less weight than the worse-off, and vice versa for losses. A concave shape of $U(q)$ has a similar effect (i.e., favouring the worse-off), but for a different reason: additional QoL improvements have less value the better the quality gets.

Now, extending this model to include sign-dependence boils down to (Attema et al., 2013; Wakker, 2010):

$\sum_{\mathrm{i}=1}^{\mathrm{m}} \pi_{\mathrm{i}}^{+} \mathrm{U}^{+}\left(\mathrm{q}_{\mathrm{i}}\right)+\sum_{\mathrm{i}=\mathrm{m}+1}^{\mathrm{n}} \pi_{\mathrm{i}}^{-} \mathrm{U}^{-}\left(\mathrm{q}_{\mathrm{i}}\right)$,

where QoL level $\mathrm{q}_{\mathrm{r}}$ is taken as a reference point. All QoL scores higher than $\mathrm{q}_{\mathrm{r}}$ are treated as gains, and all scores lower than $\mathrm{q}_{\mathrm{r}}$ are treated as losses. ${ }^{4}$

Loss aversion is an index $\lambda$ defined as a currency unit expressing the rate of exchange between gains and losses. It is captured as follows (Shalev, 2002):

$U^{r, \lambda}(q)=\left\{\begin{array}{cc}u(q) & \text { if } q \geq q_{r} \\ u\left(q_{r}\right) \mp \lambda\left[u(q)-u\left(q_{r}\right)\right] & \text { if } q<q_{r}\end{array}\right.$

where $u$ is a utility function defined on QoL. We use the power family defined by $u(q)$ $=\mathrm{q}^{\alpha}$ for gains and $\mathrm{u}(\mathrm{q})=-(-\mathrm{q})^{\beta} \operatorname{losses}$, with $\alpha, \beta>0$. For $\alpha, \beta=0, \mathrm{u}(\mathrm{q})=\ln (\mathrm{q})$ and $\mathrm{u}(\mathrm{q})=-\ln (-\mathrm{q})$, respectively. The power function is concave for gains if $\alpha<1$, convex if $\alpha>1$, and linear if $\alpha=1$. For losses, it is concave if $\beta>1$, convex if $\beta<1$ and linear if $\beta=1$. Bleichrodt et al. (2005) indicated that their equity weighting function reflected both pure equity weighting and

\footnotetext{
${ }^{4}$ Because we only used two-outcome prospects in our experiment, original prospect theory (Kahneman and Tversky, 1979) and PT (Tversky and Kahneman, 1992) coincide, so that we do not have to incorporate rankdependence. It follows that $\pi^{+}=\omega^{+}$and $\pi^{-}=\omega^{-}$. For generalizability, we refer to PT throughout this article.
} 
'insensitivity to group size'. These two concepts were distinguished by two separate parameters. However, because we only elicit one point of the equity weighting curve, we are not able to make this distinction. We instead chose to use an unspecified population size (but we explicated that the groups were always of the same size).

Because eliciting both the full utility functions and the full equity weighting functions would cause too much of a cognitive burden to our sample, we implement another approach, based on the semi-parametric method proposed by Abdellaoui et al. (2008) and subsequently applied in a health context by Attema et al. (2013). We adapted the method by replacing the outcome unit by QoL as a percentage of full health. Furthermore, instead of eliciting the decision weight attached to one particular probability, in this case we elicit the equity weight attached to a particular proportion of a group of people.

\subsection{Utility and equity weighting elicitation}

For each prospect $\mathrm{j}$ in the gain (loss) domain, we elicit a value $\overline{\mathrm{q}}^{\mathrm{j}}$ such that the subject is indifferent between the entire group gaining (losing) $\bar{q}^{\mathrm{j}}$ percentage points of QoL and the prospect that provides a higher amount (in absolute value) $\mathrm{q}_{\mathrm{a}}^{\mathrm{j}}$ to half of the group and a lower amount (in absolute value) $q_{b}^{j}$ to the other half. Value $\bar{q}^{j}$ corresponds to a constant allocation of health. In the gain domain, we have $q_{a}^{j}>q_{b}^{j}$, in the loss domain, $q_{a}^{j}<q_{b}^{j}$. Assuming the subject's preferences can be represented by PT and a power utility function, this indifference can be evaluated in the gain domain by the following equation:

$\bar{q}^{j^{\alpha}}=\omega^{+}\left(q_{a}^{j^{\alpha}}-q_{b}^{j^{\alpha}}\right)+q_{b}^{j^{\alpha}}$.

Solving this expression for $\overline{\mathrm{q}}^{\mathrm{j}}$ gives us:

$\bar{q}^{j}=\left(\omega^{+}\left(q_{a}^{j^{\alpha}}-q_{b}^{j}{ }^{\alpha}\right)+q_{b}^{j}{ }^{\alpha}\right)^{1 / \alpha}$.

The procedure is similar in the loss domain giving the following equation that enables the simultaneous estimation of the utility function parameter $\beta$ and the equity weight $\omega^{-}$through nonlinear least squares: 
$\overline{\mathrm{q}}^{\mathrm{j}}=-\left(\omega^{-}\left(\left(-\mathrm{q}_{\mathrm{a}}^{\mathrm{j}}\right)^{\beta}-\left(-\mathrm{q}_{\mathrm{b}}^{\mathrm{j}}\right)^{\beta}\right)+\left(-\mathrm{q}_{\mathrm{b}}^{\mathrm{j}}\right)^{\beta}\right)^{1 / \beta}$

\subsection{Loss aversion elicitation}

The loss aversion index $\lambda$ could be estimated by selecting an improvement of QoL $\mathrm{q}_{\mathrm{a}}$ above the reference point, and determining the loss $q_{b}$ below the reference point for which the subject was indifferent between a treatment giving a gain of $\mathrm{q}_{\mathrm{a}}$ to half of the group and $\mathrm{a}$ loss of $\mathrm{q}_{\mathrm{b}}$ to the other half, and the reference point $\mathrm{q}_{\mathrm{r}}$. Based on the assumptions introduced in Section 2.3, this gives:

$\omega^{+} q_{a}^{\alpha}-\lambda \omega^{-}\left(-q_{b}\right)^{\beta}=0$.

The mixed prospect, when solving for $\lambda$, results in the following value:

$\lambda=\frac{\omega^{+} \mathrm{q}_{\mathrm{a}}{ }^{\alpha}}{\omega^{-}\left(-\mathrm{q}_{\mathrm{b}}\right)^{\beta}}$.

\subsection{Reasons for responses}

As stressed by Bosworth et al. (2009), it is important to have qualitative information alongside quantitative estimates of preferences. Therefore, we also ask the subjects for explanations for choosing a particular option. Several previous studies have sought to explicitly ask respondents to motivate their stated health preferences (Dolan and Cookson, 2000; Lancsar et al., 2011; Schwappach and Strasmann, 2006; Skedgel et al., 2013; van Osch and Stiggelbout, 2008; van Osch et al., 2006).

\section{Experiment}

\subsection{Subjects}


A total of 517 subjects, representative for the Dutch general population, participated in the experiment.

\subsection{Procedure}

The experiment was conducted by a professional internet sampling company (Survey Sampling International). This company has much experience with internet surveys and a large representative database of subjects. The subjects were rewarded with a monetary amount to be given to a charity fund of their choice.

The experiment started with some questions regarding background characteristics. We gathered information about age, gender, number of children, marital status, income, education, health status (as classified by EQ-5D-5L) and rating of health (according to a VAS).

Indifferences were elicited by a combination of choices and matching. We started with a bisection procedure that adjusted the value of q upwards or downwards depending on the chosen option. We used two of these choices to zoom in on an indifference point. Having narrowed down the answer range accordingly, we gave the residual range of possible indifference values, and asked the subject to express their indifference value by using a scroll bar. Box 1 illustrates this procedure for a hypothetical subject.

Box 1. Illustration of the combined bisection/slider procedure

\begin{tabular}{|l|l|l|l|}
\hline Iteration & Treatment A & Treatment B & Choice \\
\hline 1 & 60 & $(40,0.5 ; 80)$ & A \\
\hline 2 & 50 & $(40,0.5 ; 80)$ & B \\
\hline 3 & Slider from 50 to 60 & $(40,0.5 ; 80)$ & Move slider to 54 \\
\hline
\end{tabular}

\subsection{Stimuli}

The experiment consisted of two different versions, with each subject being allocated randomly to one of them. In both versions it was made clear to the subjects that they should imagine a group of similarly aged people having a particular QoL in terms of percentages of full health. The QoL obviously cannot get higher than $100 \%$, so this was the maximum of our 
outcome range. In order to prevent QoL from becoming extremely low, the minimum was set to $20 \%$.

Version 1 (Unique Reference Point: URP) induced a reference point of $60 \%$ of full health, and proceeded by eliciting the utility function over both gains and losses as seen from this reference point yielding both gains and losses ranging between 0 and $40 \%$. In the mixed prospect, again, a reference point of $60 \%$ was induced. Since the reference point was the same for gains and losses in URP, we could also estimate a loss aversion index for this version.

Version 2 (Flexible Reference Point: FRP) took a different approach. Here we used three separate reference points for gains, losses, and the mixed prospect. We used the minimum outcome, $20 \%$, as the reference point in the gain part. Similarly, we took the maximum outcome, $100 \%$, as the reference point in the loss part. Taking the minimum [maximum] as the reference point allowed for eliciting the utility function for gains [losses] over the entire range. In fact, we use the same outcomes two times, but framed differently. Therefore, we have a direct test of expected utility, which predicts the same utility function for both gains and losses. If we would instead find a significant difference, this would be evidence for a framing effect. Finally, a mixed prospect was used with the reference point set at the value exactly halfway this range, i.e., at $60 \%$, so this part used the same questions as URP. In contrast to URP, we could not compute $\lambda$ with this version, because this would require a unique reference point. Nevertheless, the mixed prospect allowed us to compare the degree of inequity aversion when starting at $60 \%$ to the degree of inequity aversion in the other two parts, and to estimate the gain/loss asymmetry index. This index, which is defined as the ratio of the gain to the loss at the indifference point, assumes linear utility and equal equity weighting for gains and losses, and is used in many measurements of loss aversion (Gächter et al., 2007; Tom et al., 2007).

The utility functions for both gains and losses were elicited by the use of seven questions each. In the gain part, the subjects were given the opportunity to give the group one of two treatments that could improve their health status. The constant allocation option contained a treatment that would increase QoL with $\bar{q}$ percentage points for the entire group, whereas the variable allocation option involved a treatment that would let half of the group gain $\mathrm{q}_{\mathrm{a}}$ percentage points and the other half gain $\mathrm{q}_{\mathrm{b}}$ percentage points, with $\left|q_{b}\right|<|\bar{q}|<\left|q_{a}\right|$. We specified all QoL improvements to be transitional, lasting for one year. Subjects were told that afterward the health of the group members would (further) improve to full health. The reasons we chose a duration of the differential treatment effect of only one year were the 
following. First, it was essential that the duration was the same for all subjects, in order to guarantee homogeneity of stimuli among subjects. If we took remaining lifetime, this could be interpreted differently for different subjects and, hence, this would hamper comparability of the results. Second, a longer time span would decrease the survival probability during this span. Subjects may then accordingly reduce their valuation of the health improvement, which would again impose heterogeneity among subjects.

The instructions of the gain part told the subjects to imagine that, because of a disease, the health status of a group of $\mathrm{L}=50 / 60 / 70 / 80^{5}$ year old people had deteriorated a while ago to a level of $20 \%$ of full health. However, recently, the doctors had discovered two new treatments that could do something to combat the disease.

The health status of a group of L year old people would in the loss part deteriorate during the next year to a level of $20 \%$ of full health because of a disease. After that year, the disease would disappear naturally, and their health would return to $100 \%$. However, two treatments were also available to reduce the loss encountered during the coming year. A translation of the full instructions is available in Appendix A.

One treatment involved a gain [loss] for the entire group. The consequences of the other treatment were unequally distributed, giving a larger gain [loss] for half of the group, but a smaller gain [loss] (or none at all) for the other half of the group. The amount of the gain [loss] in the treatment giving a constant allocation was then elicited such that the subject was indifferent between the two treatments.

A mixed prospect was included to allow for estimation of the loss aversion coefficient. The subjects were instructed to consider a group of L year old people whose health had deteriorated recently to a level of $60 \%$ of full health due to unknown causes. The disease would be cured by itself in one year, causing their health to return to $100 \%$, but now also a treatment has become available that may improve these people's health immediately. However, the consequences of this treatment are unequally allocated, because for half of the patients it generates serious side-effects, reducing their health even further, to a level of $\mathrm{q}<60 \%$. For the other half of the group, the treatment has no side-effects and their health immediately improves to $80 \%$.

The stimuli of the prospects of these questions are shown in Table 1.

Table 1. Stimuli of the gain and loss prospects for FRP and URP (in terms of absolute value of changes)

\begin{tabular}{l|l|l|l|l|l|l|l|} 
FRP & $\mathrm{j}=1$ & $\mathrm{j}=2$ & $\mathrm{j}=3$ & $\mathrm{j}=4$ & $\mathrm{j}=5$ & $\mathrm{j}=6$ & $\mathrm{j}=7$ \\
\hline
\end{tabular}

\footnotetext{
${ }^{5}$ Each subject was randomly allocated to one of these four age versions.
} 


\begin{tabular}{|c|c|c|c|c|c|c|c|}
\hline$\left|q_{a}\right|$ & 22 & 39 & 78 & 53 & 72 & 78 & 80 \\
\hline$\left|q_{b}\right|$ & 0 & 1 & 2 & 8 & 29 & 42 & 57 \\
\hline $\mathrm{URP}$ & $\mathrm{j}=1$ & $\mathrm{j}=2$ & $\mathrm{j}=3$ & $\mathrm{j}=4$ & $\mathrm{j}=5$ & $\mathrm{j}=6$ & $\mathrm{j}=7$ \\
\hline$\left|q_{a}\right|$ & 11 & 26 & 38 & 33 & 29 & 39 & 40 \\
\hline$\left|q_{b}\right|$ & 0 & 1 & 2 & 8 & 19 & 20 & 27 \\
\hline
\end{tabular}

We only used a proportion of one-half for the treatment yielding an unequal allocation. The order of the seven prospects was random. The experiment always started with the gain part. After extensive piloting using university staff, we deliberately chose this approach instead of randomizing because the testers indicated that the gain task was easier to understand. After performing this task they were more familiar with the situation, so that they were better able to answer the loss part. For the same reasons, Li et al. (2015) and Vieider et al. (2015) recommended to have gain questions preceding loss questions. In addition, EtchartVincent and l'Haridon (2011) and Vieider et al. (2015) tested for order effects between gains and losses, but did not find any.

After that, the loss and mixed prospects were asked in random order, although these parts were not interspersed. The latter would require more cognitive effort by the subjects, because they would then repeatedly have to change perspective from gains to losses, and vice versa, which would likely threaten data reliability.

Since we did not know the subjects' reference points, we induced a status quo (i.e. an initial health state) that was the same for all. It may be the case that subjects adopted the status quo as their reference points, but they may also have framed the outcomes as deviations from their own reference point (e.g., what they consider to be a normal health level for people of a particular age), or they may have constructed a reference point according to some weighted average of these two levels. An adoption of the status quo implemented in the experiment would predict no difference for different age groups, whereas the other two possibilities may evoke differences between them. Therefore, a significant difference between age groups would reject the hypothesis that subjects perceive the status quo as their reference point, but instead replace or combine it with some other, age-dependent, reference point. In our experiment we also made an attempt to elicit this point by asking the subjects for normal health levels for people of several ages, as further explained below.

\subsection{Explanations}


We selected one choice in each part that was followed by a question about the reason why this particular option was chosen. In the gain part, we asked subjects who valued the equal prospect in the first choice of $\mathrm{j}=1$ over the unequal prospect did so because of an equity heuristic, because of diminishing marginal utility $^{6}$, or some other reason. Likewise, subjects opting for the unequal prospect could choose between an argument of giving one part of the group a worthwhile improvement, an argument of increasing marginal utility, and some other argument.

Subjects choosing the equal allocation in the first choice of $j=7$ of the loss part could indicate a reason of inequity aversion (convex equity function), concave utility, or another or no specific reason. Those choosing the unequal allocation could opt for the argument of ensuring at least part of the group would keep its current health level (concave equity), convex utility, or again another or no specific reason.

For the mixed prospect we offered an argument of utility curvature or steepness (i.e., loss aversion) to the people not choosing the treatment in the first choice, as well as an argument of fairness, and again the possibility to give other arguments or having none. Finally, those picking the treatment had the opportunity to indicate an argument of ensuring at least one part of the group would experience a health improvement, an argument of utility curvature or steepness (i.e., gain seeking), or some other or no particular argument. The exact framing of the questions can be found in Appendix B.

\subsection{Subjective health expectations}

After the main experiment, we elicited the subject's perceived normal health level at different ages. The latter was accomplished by using the EQ-5D-5L classification system and asking for each of its five dimensions, at what age subjects thought it was normal to experience deteriorations, and to what degree (using the five levels of the EQ-5D, varying between no problems to severe problems). This question was being repeated for the ages 40 , $50,60,70,80$ and 90 years. Subjects could also indicate they considered problems on some dimension never to be normal. The answers enabled us to compute for each age which EQ5D-5L state was considered normal. Furthermore, by applying the Dutch national tariff set

\footnotetext{
${ }^{6}$ As shown in Appendix B, this means the subjects value a gain of 20 to 31 more than a further improvement from 31 to 42 .
} 
for EQ-5D-5L states (www.euroqol.org), we could assign a QoL score to these states. As explained later, this was used as an approximation of subjects' subjective reference points.

\subsection{Analysis}

A subject was classified as inequity averse [inequity seeking] if at least 5 out of 7 questions produced an inequity averse [seeking] answer (i.e., a $\overline{\mathrm{q}}^{\mathrm{j}}$ lower [higher] than the expected value of the treatment). This allowed taking into account response error. Box 2 exemplifies this classification for the beneath answers of a virtual subject.

\section{Box 2. Example of classification}

\begin{tabular}{|c|c|c|c|c|c|}
\hline Prospect & Treatment B & EV & $\bar{q}^{j}$ & Classification & $\begin{array}{c}\text { Atkinson } \\
\text { Index }\end{array}$ \\
\hline 1 & $(22,0.5 ; 0)$ & 11 & 10 & Inequity averse & 0.091 \\
\hline 2 & $(39,0.5 ; 1)$ & 20 & 15 & Inequity averse & 0.250 \\
\hline 3 & $(78,0.5 ; 2)$ & 40 & 30 & Inequity averse & 0.250 \\
\hline 4 & $(53,0.5 ; 8)$ & 30.5 & 35 & Inequity seeking & -0.148 \\
\hline 5 & $(72,0.5 ; 29)$ & 50.5 & 52 & Inequity seeking & -0.030 \\
\hline 6 & $(78,0.5 ; 42)$ & 60 & 50 & Inequity averse & 0.167 \\
\hline 7 & $(80,0.5 ; 57)$ & 68.5 & 64 & Inequity averse & 0.066 \\
\hline \multicolumn{7}{|c|}{ Inequity averse answers: 5; inequity seeking answers: 2. } \\
\hline
\end{tabular}

Because the data were not normally distributed (Kolmogorov Smirnov test: $\mathrm{p}<0.01$ for all $\bar{q}^{j}$ ), we performed nonparametric statistical tests (Wilcoxon signed ranks tests for withinsubjects analyses and Mann-Whitney tests for between-subjects analyses). The distribution of $\bar{q}^{j}$ values was reasonably symmetric, so it was not necessary to first transform them. Twotailed p-values are reported.

A convenient index can be derived from the HRSW function that provides a measure of inequity aversion: the Atkinson index (Atkinson, 1970). For gains, this is simply 1 minus the ratio of $\bar{q}^{j}$ to the expected value (EV) of each prospect: $1-\bar{q}^{j} / \mathrm{EV}$ (see also Dolan and 
Robinson, 2001). For losses, it is $\bar{q}^{j} / \mathrm{EV}-1$. Therefore, we also present the Atkinson indices as a summary measure of the amount of inequity aversion (also included in Box 2).

\section{Results}

The following table provides a comparison between the characteristics of the sample and those of the Dutch population. The sample appears to be representative on Gender, Income Groups, Middle Education, and Health Status. Respondents in the sample are older than the general Dutch population, have more kids and the share of higher education is higher among them.

Table 2. Background statistics: full sample ( $n=517$, of which in 264 in FRP and $n=253$ in URP) and statistics for the general population in the Netherlands

\begin{tabular}{|c|c|c|c|c|}
\hline & \multicolumn{2}{|c|}{ Full sample } & \multicolumn{2}{|c|}{ General population } \\
\hline Variable & Percentage & Mean & Population average & Source \\
\hline Age & & 44.4 & 40.8 & $\frac{\text { www.cbs.nl }}{\text { population } 2013}$ \\
\hline Gender ( $\%$ male $)$ & $49.3 \%$ & & $49.5 \%$ & \\
\hline Income groups: & & & & $\frac{\text { www.cbs.nl }}{\text { spendable income }} 2013$ \\
\hline$<€ 1000$ & 10.3 & & 8 & \\
\hline$€ 1000-<€ 2000$ & 29.4 & & 31.1 & \\
\hline$€ 2000-<€ 3000$ & 24.2 & & 25.1 & \\
\hline$€ 3000-<€ 4000$ & 18.2 & & 16.8 & \\
\hline$>€ 3999$ & 18.0 & & 18.9 & \\
\hline Education: & & & & $\frac{\text { www.cbs.nl }}{\text { labor force } 2013}$ \\
\hline Lower & 22.2 & & 30.7 & \\
\hline Middle & 38.1 & & 40.7 & \\
\hline Higher & 39.7 & & 28.5 & \\
\hline \multicolumn{5}{|l|}{ Health status } \\
\hline $\begin{array}{l}\text { EQ-5D (Dutch } \\
\text { tariff) }\end{array}$ & & 0.84 & 0.89 & $\begin{array}{l}\text { Szende et al. (2014), p. } \\
29\end{array}$ \\
\hline VAS own health & & 79.4 & 81.4 & $\begin{array}{l}\text { Szende et al. (2014) p. } \\
32\end{array}$ \\
\hline Completion time (mins.) & & 24.1 & - & \\
\hline
\end{tabular}

Sources: Statistics Netherlands (CBS), Szende et al. (2014) and authors' calculations.

The data regarding expected normal health states for different age classes indicate a steep decline in the amount of health the higher the age (Figure 1). The average expected QoL declines from 0.94 for 40 -year olds to 0.08 for 90 -year olds. Most strikingly, subjects expect people of ages 80 and above to live in poor health states. For 90 -year olds, the median 
expected health state was as low as EQ-5D-5L state 55553, which is lowest on four of the domains and is assigned a negative QoL value according to the Dutch tariff (EuroQol Group, 2013). These patterns clearly resemble previous findings in this area (Brouwer and van Exel, 2005; Péntek et al., 2012).

Figure 1. Error plot of normal health levels at different ages

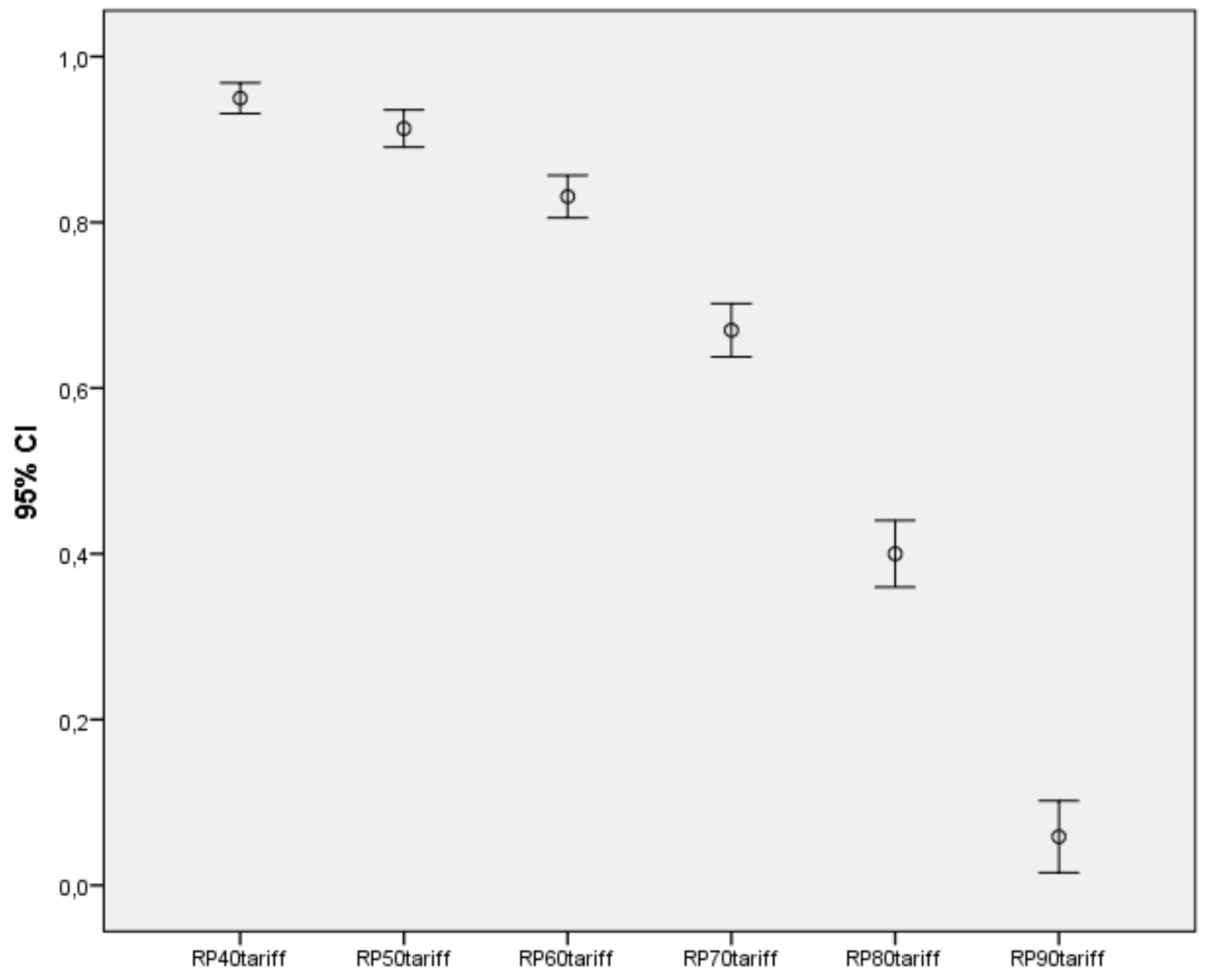

\subsection{CAEs and inequity attitude}

$\underline{\text { FRP }}$

Table 3 displays the medians of the $\bar{q}^{j}$ as well as their corresponding Atkinson indices for each prospect. 
Table 3. Median $\bar{q}^{j}$ s (interquartile ranges), FRP

\begin{tabular}{|c|c|c|c|c|c|}
\hline $\mathrm{j}$ & $\bar{q}^{j}$ Gains & Atkinson Index & $\begin{array}{c}\text { Standard deviation } \\
\text { of the prospect }\end{array}$ & $\bar{q}^{j}$ Losses & Atkinson Index \\
\hline 1 & $10.5(6 ; 14)$ & $0.045(-0.273 ; 0.455)$ & 11 & $14(10 ; 17)$ & $0.273(-0.91 ; 0.545)$ \\
\hline 2 & $19(11 ; 22)$ & $0.05(-0.10 ; 0.45)$ & 19 & $22(11 ; 31)$ & $0.10(-0.45 ; 0.55)$ \\
\hline 3 & $33(16 ; 56)$ & $0.175(-0.40 ; 0.60)$ & 38 & $59(33 ; 59)$ & $0.475(-0.175 ; 0.475)$ \\
\hline 4 & $29(18 ; 40)$ & $0.049(-0.311 ; 0.410)$ & 22.5 & $35(29 ; 41)$ & $0.148(-0.049 ; 0.344)$ \\
\hline 5 & $45(37 ; 58)$ & $0.109(-0.149 ; 0.267)$ & 21.5 & $58(45 ; 60)$ & $0.149(-0.109 ; 0.188)$ \\
\hline 6 & $57.5(53 ; 63)$ & $0.042(-0.50 ; 0.117)$ & 18 & $61.5(53 ; 68.75)$ & $0.025(-0.117 ; 0.142)$ \\
\hline 7 & $68(62 ; 74)$ & $0.007(-0.08 ; 0.095)$ & 11.5 & $68(62 ; 73)$ & $-0.007(-0.095 ; 0.066)$ \\
\hline Overall & & $0.049(-0.134 ; 0.267)$ & & & $0.059(-0.109 ; 0.344)$ \\
\hline
\end{tabular}

For gains, $56.9 \%[37.2 \%, 5.9 \%]$ of the answers were consistent with inequity aversion [inequity seeking, inequity neutrality]. Similar proportions were observed for losses: $56.3 \%$ $[38.7 \%, 4.9 \%$ ] of the answers reflected inequity aversion [inequity seeking, inequity neutrality].

The classification of subjects in terms of inequity attitude for gains and losses is presented in Table 4a, and shows a similar picture as the one derived from the individual responses. The largest group consisted of subjects who were inequity averse over the whole domain $(28.0 \%)$. There were also relatively many subjects again who were inequity averse for losses and not classified for gains or vice versa (11.7\% resp. 14.0\%). Other subjects could not be classified for both domains (15.2\%). The proportion of inequity averse subjects for both gains and losses was significantly higher than the proportion of inequity seeking subjects (binomial test, $\mathrm{p}<0.01$ ).

Table 4a. Classification according to $\bar{q}^{j}(F R P)$

\begin{tabular}{|l|l|c|c|c|c|c|c|}
\hline & Losses & & & & & & \\
\hline & $\begin{array}{c}\text { Inequity } \\
\text { averse }\end{array}$ & $\begin{array}{c}\text { Inequity } \\
\text { neutral }\end{array}$ & $\begin{array}{c}\text { Inequity } \\
\text { seeking }\end{array}$ & Mixed & Total & $\begin{array}{c}\text { Mean } \\
\text { AI }\end{array}$ \\
\hline Gains & $\begin{array}{l}\text { Inequity } \\
\text { averse }\end{array}$ & 74 & 0 & 11 & 37 & 122 & 0.24 \\
\hline & $\begin{array}{l}\text { Inequity } \\
\text { neutral }\end{array}$ & 0 & 0 & 0 & 0 & 0 & -0.01 \\
\hline & $\begin{array}{l}\text { Inequity } \\
\text { seeking }\end{array}$ & 7 & 0 & 33 & 16 & 56 & -0.31 \\
\hline & Mixed & 31 & 0 & 15 & 40 & 86 & 0.04 \\
\hline & Total & 112 & 0 & 59 & 93 & 264 & \\
\hline & Mean AI & 0.30 & & -0.23 & 0.06 & 0.10 & \\
\hline
\end{tabular}


Since subjects were only classified as inequity neutral if they provided the EV as their CAE in at least 5 of the 7 questions using the above criterion, we also classified subjects using a criterion which allowed for a higher response error. In particular, this criterion also classified subjects as inequity neutral if they had a CAE that was within $+/-2.5 \%$ of the EV at least five times. As shown in Table 4b, the classifications are quite robust to allowance for error. $^{7}$

Table 4b. Classification according to $\bar{q}^{j}$ when including an error margin for inequity neutrality (FRP)

\begin{tabular}{|l|l|c|c|c|c|c|c|}
\hline & Losses & & & & & & Mixed \\
\hline Gains & $\begin{array}{l}\text { Inequity } \\
\text { averse }\end{array}$ & $\begin{array}{c}\text { Inequity } \\
\text { neutral } \\
\text { avequity }\end{array}$ & 67 & 0 & $\begin{array}{c}\text { Inequity } \\
\text { seeking }\end{array}$ & $\begin{array}{c}\text { Mean } \\
\text { AI }\end{array}$ \\
\hline & $\begin{array}{l}\text { Inequity } \\
\text { neutral }\end{array}$ & 0 & 5 & 7 & 36 & 110 & 0.25 \\
\hline & $\begin{array}{l}\text { Inequity } \\
\text { seeking }\end{array}$ & 6 & 1 & 28 & 19 & 54 & -0.32 \\
\hline & Mixed & 32 & 4 & 12 & 46 & 94 & 0 \\
\hline & Total & 105 & 10 & 47 & 102 & 264 & 0.04 \\
\hline & Mean AI & 0.31 & 0.01 & -0.27 & 0.06 & 0.10 & \\
\hline
\end{tabular}

Stochastic dominance, defined by the assignment of a higher indifference value to a prospect with at least one better outcome and no worse outcome, was also sometimes violated. A significant minority of our subjects violated dominance in one or more questions, in that their indifference value was equal to the lowest or highest outcome of the prospect. This held for $5.25 \%$ of the CAEs in the gain domain and $7.31 \%$ in the loss domain.

URP

Table 5 displays the medians of the $\bar{q}^{j}$ as well as their corresponding Atkinson indices for each prospect.

Table 5. Median $\bar{q}^{j}$ S (interquartile ranges), FRP

\footnotetext{
${ }^{7}$ We also classified subjects using a 5\% upper and lower margin (see Appendix C for results). This mainly resulted in a higher number of mixed classifications at the cost of inequity averse and seeking subjects, but again did not change the main conclusions.
} 


\begin{tabular}{|c|c|c|c|c|c|}
\hline $\mathrm{j}$ & $\bar{q}^{j}$ Gains & Atkinson Index & $\begin{array}{c}\text { Standard deviation } \\
\text { of the prospect }\end{array}$ & $\bar{q}^{j}$ Losses & Atkinson Index \\
\hline 1 & $5(3-7)$ & $0.091(-0.273 ; 0.455)$ & 5.5 & $7(5-8)$ & $0.273(-0.091 ; 0.455)$ \\
\hline 2 & $13(7-14)$ & $0.037(-0.37 ; 0.481)$ & 12.5 & $15(12-20)$ & $0.111(-0.111 ; 0.481)$ \\
\hline 3 & $11(11-20)$ & $0.450(0 ; 0.450)$ & 18 & $25(20-29)$ & $0.250(0 ; 0.450)$ \\
\hline 4 & $18(14-20)$ & $0.122(0.024 ; 0.317)$ & 12.5 & $22(20-26)$ & $0.073(-0.024 ; 0.268)$ \\
\hline 5 & $22(22-24)$ & $0.083(0 ; 0.083)$ & 5 & $24(22-27)$ & $0(-0.083 ; 0.125)$ \\
\hline 6 & $28(25-30)$ & $0.051(-0.017 ; 0.153)$ & 9.5 & $30(25-34)$ & $0.017(-0.153 ; 0.153)$ \\
\hline 7 & $30(30-35)$ & $0.104(-0.045 ; 0.104)$ & 6.5 & $34(33-37)$ & $0.015(-0.015 ; 0.104)$ \\
\hline Overall & & $0.083(-0.169 ; 0.317)$ & & & $0.045(-0.083 ; 0.268)$ \\
\hline
\end{tabular}

For gains, $66.2 \%[28.2 \%, 5.6 \%]$ of the answers were consistent with inequity aversion [inequity seeking, inequity neutrality]. The higher amount of inequity aversion for URP than for FRP was not to be expected, because of the smaller range in case of URP, but it was nevertheless significant (Mann-Whitney test comparing total amounts of inequity averse responses per subject, $\mathrm{p}<0.01)$.

In the loss framing, this pattern was similar, albeit with some more inequity seeking individuals: $58.5 \%[35.4 \%, 6.1 \%]$ of the answers reflected inequity aversion [inequity seeking, inequity neutrality]. This was very similar to the findings for URP (Mann-Whitney test for inequity averse answers per subject, $\mathrm{p}=0.419$ ).

The classification of subjects in terms of inequity attitude for gains and losses is presented in Table 6a, and shows a similar picture as the one derived from the separate responses. The largest group consisted of subjects who were inequity averse over the whole domain (31.8\%). There were also relatively many subjects who were inequity averse for either gains or losses and not classified for the other domain $(15.5 \%$ for gains and $11.0 \%$ for losses). $12.1 \%$ could not be classified for both domains. Only $4.5 \%$ were classified as inequity seeking for both gains and losses. The proportion of universally inequity averse subjects was higher than the proportion of inequity seeking subjects (binomial test, $\mathrm{p}<0.01$ ).

Table 6a. Classification according to $\bar{q}^{j}$ (URP)

\begin{tabular}{|l|l|c|c|c|c|c|c|}
\hline & Losses & & & & & & \\
\hline & & $\begin{array}{c}\text { Inequity } \\
\text { averse }\end{array}$ & $\begin{array}{c}\text { Inequity } \\
\text { neutral }\end{array}$ & $\begin{array}{c}\text { Inequity } \\
\text { seeking }\end{array}$ & Mixed & Total & $\begin{array}{c}\text { Mean } \\
\text { AI }\end{array}$ \\
\hline Gains & $\begin{array}{l}\text { Inequity } \\
\text { averse }\end{array}$ & 84 & 0 & 21 & 41 & 146 & 0.21 \\
\hline & $\begin{array}{l}\text { Inequity } \\
\text { neutral }\end{array}$ & 0 & 0 & 0 & 0 & 0 & \\
\hline
\end{tabular}




\begin{tabular}{|l|l|c|c|c|c|c|c|}
\hline & $\begin{array}{l}\text { Inequity } \\
\text { seeking }\end{array}$ & 4 & 0 & 12 & 10 & 26 & -0.24 \\
\hline & Mixed & 29 & 0 & 20 & 32 & 81 & 0.01 \\
\hline & Total & 117 & 0 & 53 & 83 & 253 & 0.10 \\
\hline & Mean AI & 0.27 & & -0.20 & 0.03 & 0.09 & \\
\hline
\end{tabular}

An alternative classification accounting for error (+/-2.5\% margin) by inequity neutral subjects was also performed for URP and again gave similar results as in the initial classification, as demonstrated by Table $6 \mathrm{~b}$.

Table 6b. Classification according to $\bar{q}^{j}$ when including an error margin for inequity neutrality (URP)

\begin{tabular}{|l|l|c|c|c|c|c|c|}
\hline & Losses & & & & & & Mixed \\
\hline Gains & $\begin{array}{c}\text { Inequity } \\
\text { averse }\end{array}$ & $\begin{array}{c}\text { Inequity } \\
\text { neutral }\end{array}$ & $\begin{array}{c}\text { Inequity } \\
\text { seeking }\end{array}$ & $\begin{array}{c}\text { Mean } \\
\text { AI }\end{array}$ \\
\hline & $\begin{array}{l}\text { Inequity } \\
\text { neutral }\end{array}$ & 69 & 2 & 15 & 41 & 128 & 0.22 \\
\hline & $\begin{array}{l}\text { Inequity } \\
\text { seeking }\end{array}$ & 2 & 0 & 0 & 2 & 2 & -0.01 \\
\hline & Mixed & 29 & 5 & 7 & 10 & 19 & -0.26 \\
\hline & Total & 100 & 7 & 32 & 114 & 253 & 0.10 \\
\hline & Mean AI & 0.29 & 0.01 & -0.27 & 0.02 & 0.09 & \\
\hline
\end{tabular}

There are also significant differences in the Atkinson indices of low and high outcome prospects. In particular, subjects were more inequity averse for lower gain prospects than for higher gain prospects. Vice versa, subjects were less inequity averse for higher loss prospects than for lower loss prospects. We found evidence for such effects both in FRP and in URP.

Stochastic dominance was violated for $3.78 \%$ of the CAEs in the gain domain and $8.13 \%$ in the loss domain.

\section{Comparing gains and losses}

We compared the $\bar{q}^{j}$ in terms of final values between gain and loss prospects offering similar final values in FRP. For example, we compared prospect $\mathrm{j}=1$ with the lowest gain to prospect $j=7$ with the highest loss, and vice versa. We also compared $j=2$ with $j=6, j=4$ with $\mathrm{j}=5$, and $\mathrm{j}=3$ with itself. We found lower values for losses than gains for five out of the seven comparisons $(p<0.05)$. Lower values for losses corresponded to the five prospects with the lowest expected values. We also compared the Atkinson indices between these prospects. In these comparisons we again found more inequity aversion for losses than for gains for five 
out of the seven comparisons (Wilcoxon signed ranks test, $\mathrm{p}<0.05$ ), but also more inequity aversion for gains for the other two comparisons $(p<0.01$ for $j=1$ for gains $v s . j=7$ for losses, and for $\mathrm{j}=2$ for gains vs. $\mathrm{j}=6$ for losses).

For URP, the final health levels were different by design, so here we compared the Atkinson indices of prospects with the same absolute changes (e.g. $\mathrm{j}=1$ with itself and so on). We found lower Atkinson indices for losses than for gains for three of the seven comparisons $(\mathrm{p}<0.05)$, and a higher index for losses for one $(\mathrm{p}<0.01)$.

\section{$\underline{\text { Reference points effects within gains/losses }}$}

For one of the questions ( $j=6$ in FRP and $j=3$ in URP), the final outcomes of the prospects were the same between the two versions, albeit that the starting point differed. This correspondence enabled us to test for reference point effects. For gains, with final outcomes $62 \%$ and $98 \%$, we observed a difference between the two versions (Mann-Whitney test, $\mathrm{p}<0.01)$ with URP associated with more inequity aversion. For losses, with final outcomes $22 \%$ and $58 \%$, we found more inequity aversion for FRP $(\mathrm{p}<0.01)$. In both cases, we found evidence for a reference point effect: subjects were more inequity averse for the same outcomes when their initial health state was higher.

\section{Mixed prospect (FRP and URP combined)}

There was also a high degree of inequity aversion in the mixed prospects. In total, $68.7 \%$ of the responses were inequity averse, $20.3 \%$ were inequity seeking, and $11.0 \%$ were classified as inequity neutral. This degree of inequity aversion was comparable to the degree of risk aversion for mixed prospects found in previous studies eliciting loss aversion with monetary outcomes (Abdellaoui et al., 2008) or health outcomes (Attema et al., 2013).

\subsection{Comparison of age groups}

Mann-Whitney tests indicate a significant difference between the within-subject Atkinson indices of the sample with 50/60/70 year olds and the sample with 80-year olds. Atkinson indices differed between 70 and 80 years old for FRP in the gain domain and for URP in both domains, with higher inequity aversion for 80 years old people. We also found evidence $(\mathrm{p}<0.06)$ for inequity aversion between $50 / 60$ and 80 years old for gains in FRP and losses in URP. People get more inequity averse when deciding on behalf of a group of 80 than on behalf of 50,60 and 70 year olds. 


\subsection{Parametric estimates}

Table 7 gives an overview of the parameter estimates when fitting the power family. The results make clear there is a considerable amount of concavity for both gains and losses, as well as a significant amount of equity weighting.

FRP

The power estimates $\alpha$ and $\beta$ both indicate concavity in FRP, although the estimate only deviates significantly from 1 for losses ( $p=0.54$ for gains; $p<0.01$ for losses). The estimates are larger than 0 , rejecting the Cobb-Douglas specification $(\mathrm{p}<0.01)$. The estimates of both $\omega^{+}$and $\omega^{-}$are smaller than $0.5(\mathrm{p}<0.01)$. We did not estimate the loss aversion index here, because the reference points for gains and losses were different.

\section{$\underline{\mathrm{URP}}$}

Both power estimates again indicate concavity in URP, although it is not significantly different from 1 for gains ( $p=0.61$ for gains; $p<0.01$ for losses). The Cobb-Douglas specification is again rejected, with both estimates being higher than $0(p<0.01)$. The estimate of $\omega^{+}$is substantially smaller than $0.5(\mathrm{p}<0.01)$, suggesting most of the inequity aversion for gains can be attributed to differential weighting of the two groups in this version. For losses the results are similar to those of FRP, with the estimate of $\omega^{-}$not significantly different from $0.5(\mathrm{p}=0.06)$.

The estimate of $\lambda$ indicates loss aversion $(\mathrm{p}<0.01)$. However, this estimate is an underestimation of the amount of loss aversion, because 49 subjects were excluded from this analysis as their answer to the mixed was prospect was $\mathrm{L}=0$, implying infinite loss aversion. Including these subjects in the analysis, the median increases to 3.65.

Table 7a. Estimation results, based on individual data (FRP)

\begin{tabular}{|l|l|l|l|l|l|l|}
\hline \multicolumn{2}{|c|}{} & $\alpha$ & $\omega^{+}$ & $\beta$ & $\omega^{-}$ & $\lambda$ \\
\hline \multirow{2}{*}{} & Median & 0.88 & 0.42 & 1.37 & 0.49 & -- \\
\cline { 2 - 7 } & IQR & $0.40-1.50$ & $0.24-0.59$ & $0.85-3.07$ & $0.22-0.63$ & -- \\
\hline
\end{tabular}

Table 7b. Estimation results, based on individual data (URP)

\begin{tabular}{|l|l|l|l|l|l|l|}
\hline & $\alpha$ & $\omega^{+}$ & $\beta$ & $\omega^{-}$ & $\lambda$ & $\lambda$ incl. infinite LA \\
\hline Median & 0.98 & 0.37 & 1.16 & 0.48 & 1.44 & 3.65 \\
\hline
\end{tabular}




\begin{tabular}{|l|l|l|l|l|l|l|}
\hline IQR & $0.62-1.38$ & $0.25-0.53$ & $0.95-2.36$ & $0.29-0.68$ & $0.51-21.3$ & $0.65-28122$ \\
\hline
\end{tabular}

To account for the impact of socio-demographic variables, we estimated the model on pooled data, taking into account gender, age, education and income. We also included age groups and the tariff at 40 . The latter allows accounting for the heterogeneity in perceived life quality. For gender, women were taken to be the reference. For age, we took the average age. For education and income we took the lowest level as a reference. For age groups, the reference was the 50-years old group. For the tariff at 40, value 1 was taken to be the reference. Table 8 shows the results of the estimation. Evidence on the impact of sociodemographic factors was mixed. We found almost no gender or income effect, except on inequity aversion for losses in URP where both effects went in opposite direction. Here, men were found to be more inequity seeking for losses. The main effect of age was to increase the convexity of the utility function in both FRP and URP. Education had no effect in URP, but impacted both utility and weighting for losses in FRP, with higher education associated with more concavity in utility and less weighting. Both have opposite effects on inequity aversion. Finally, deviations from a value of 1 for the tariff at 40 mostly impacted the shape of the utility function in the loss domain in both versions, but we observed opposite signs here, which is difficult to interpret.

Table 8. Estimation on pooled data with observable characteristics

\begin{tabular}{|c|c|c|c|c|c|c|c|c|}
\hline \multirow[t]{2}{*}{ FRP } & \multicolumn{2}{|l|}{$\alpha$} & \multicolumn{2}{|l|}{$\omega^{+}$} & \multicolumn{2}{|l|}{$\beta$} & \multicolumn{2}{|l|}{$\omega^{-}$} \\
\hline & Parameter & Std. Err. & Parameter & Std. Err. & Parameter & Std. Err. & Parameter & Std. Err. \\
\hline Reference & $0.847 *$ & 0.146 & $0.545^{*}$ & 0.040 & $0.911 *$ & 0.210 & $0.581 *$ & 0.043 \\
\hline Gender & -0.057 & 0.108 & 0.006 & 0.029 & -0.164 & 0.171 & 0.032 & 0.033 \\
\hline Age & -0.004 & 0.004 & 0.001 & 0.001 & $0.012 *$ & 0.006 & 0.000 & 0.001 \\
\hline Education & 0.042 & 0.072 & -0.015 & 0.020 & $0.296^{*}$ & 0.111 & $-0.044^{*}$ & 0.022 \\
\hline Income & 0.031 & 0.069 & -0.007 & 0.019 & 0.066 & 0.111 & -0.019 & 0.021 \\
\hline Age group & -0.020 & 0.049 & -0.014 & 0.013 & 0.107 & 0.078 & -0.022 & 0.015 \\
\hline Tariff40 & -0.049 & 0.381 & 0.100 & 0.104 & $-1.949 *$ & 0.918 & 0.220 & 0.125 \\
\hline \multirow[t]{2}{*}{ URP } & $\alpha$ & & $\omega^{+}$ & & $\beta$ & & $\omega^{-}$ & \\
\hline & Parameter & Std. Err. & Parameter & Std. Err. & Parameter & Std. Err. & Parameter & Std. Err. \\
\hline Reference & $0.829 *$ & 0.139 & $0.375^{*}$ & 0.036 & $1.446^{*}$ & 0.221 & $0.539 *$ & 0.042 \\
\hline Gender & 0.037 & 0.109 & 0.026 & 0.028 & 0.103 & 0.160 & $-0.062 *$ & 0.032 \\
\hline Age & 0.004 & 0.004 & -0.001 & 0.001 & $-0.013 *$ & 0.005 & 0.002 & 0.001 \\
\hline Education & 0.016 & 0.074 & 0.015 & 0.019 & 0.028 & 0.112 & -0.020 & 0.022 \\
\hline Income & 0.087 & 0.075 & -0.015 & 0.019 & -0.179 & 0.108 & $0.059^{*}$ & 0.021 \\
\hline Age group & -0.033 & 0.048 & 0.016 & 0.012 & -0.034 & 0.072 & -0.018 & 0.014 \\
\hline
\end{tabular}




\begin{tabular}{|l|l|l|l|l|l|l|l|l|}
\hline Tariff40 & -0.251 & 0.399 & -0.009 & 0.097 & $0.653 *$ & 0.261 & $-0.225 *$ & 0.056 \\
\hline
\end{tabular}

*: significant at $5 \%$.

\subsection{Explanations provided by subjects}

\section{$\underline{\text { Gains }}$}

For gains, in both versions there is a clear preference for the argument that all people would benefit over the argument of diminishing marginal utility $(p<0.01)$. Hence, there is evidence that a majority of the subjects are inequity averse because of equity concerns instead of utility maximization. Indeed, this explanation is consistent with our empirical estimates, which indicate underweighting of the group gaining the most. The argumentative evidence therefore underlines the necessity to model this kind of preferences in terms of both a utility function and an equity function.

Table 9. Arguments for gain prospects

\begin{tabular}{|l|c|c|c|c|c|}
\hline FRP & $\begin{array}{c}\text { Argument 1 } \\
\text { 'Equity' }\end{array}$ & $\begin{array}{c}\text { Argument 2 } \\
\text { 'Utility' }\end{array}$ & Other argument & No argument & Total \\
\hline Treatment A & 141 & 21 & 5 & 18 & 185 \\
\hline Treatment B & 33 & 31 & 3 & 12 & 79 \\
\hline Total & 174 & 52 & 8 & 30 & 264 \\
\hline URP & & & & & \\
\hline Treatment A & 135 & 17 & 3 & 16 & 171 \\
\hline Treatment B & 27 & 44 & 2 & 9 & 82 \\
\hline Total & 162 & 61 & 5 & 25 & 253 \\
\hline
\end{tabular}

For URP, the number of subjects choosing Treatment B in this question was less than half of the number of subjects choosing Treatment A. Among those, there was a majority stating Argument 2 (utility argument) as their reason for preferring Treatment B, although the difference was not as overwhelming as for the individuals picking Treatment A. However, the difference was significant according to a binomial test $(\mathrm{p}=0.028)$. This pattern suggests that there are more people choosing the unequal treatment because of a convex utility function than because of threshold reasoning, although for FRP, there was no significant difference between the frequencies of the arguments $(\mathrm{p}=0.45)$.

We also compared the utility and equity weight estimates between the subjects choosing the different arguments, but these did not differ (Mann-Whitney test, $\mathrm{p}>0.21$ ). 
For losses in URP, of the $80 \%$ who opted for the constant allocation treatment, twice as many subjects chose Argument 2 as Argument 1, indicating a clear preference for an argument pointing to a concave utility function over an argument relating to equity (binomial test, $\mathrm{p}<0.01$ ). Consequently, it seems that losses evoke more utility reasoning than gains. The difference in popularity of the arguments was less marked for FRP than URP, though still significant $(\mathrm{p}=0.03)$.

Table 10. Arguments for loss prospects

\begin{tabular}{|l|c|c|c|c|c|}
\hline FRP & $\begin{array}{c}\text { Argument 1 } \\
\text { 'Equity' }\end{array}$ & $\begin{array}{c}\text { Argument 2 } \\
\text { 'Utility' }\end{array}$ & Other argument & No argument & Total \\
\hline Treatment A & 65 & 89 & 6 & 15 & 175 \\
\hline Treatment B & 53 & 21 & 2 & 13 & 89 \\
\hline Total & 118 & 110 & 8 & 28 & 264 \\
\hline URP & & & & & \\
\hline Treatment A & 62 & 118 & 0 & 20 & 200 \\
\hline Treatment B & 31 & 9 & 1 & 12 & 53 \\
\hline Total & 93 & 127 & 1 & 32 & 253 \\
\hline
\end{tabular}

For those choosing Treatment B, there was a majority stating Argument 1 (equityrelated) as their argument (binomial test, $\mathrm{p}<0.01$ for both versions). Hence, these people opted for the unequal allocation in order for at least some people not to lose anything, which may be considered to be similar in spirit as the common observation where people prefer a monetary loss gamble over a sure loss if the former involves a chance of preventing a loss. A lower fraction of subjects indicated to have a convex utility function for losses, which would be consistent with Argument 2. In other words, people who prefer the unequal allocation treatment over the equal allocation tend to do so because of a reason that may be classified as giving more weight to the group of people with the best prospects after treatment (i.e., maintaining their present health status), rather than their utility function being convex. Again, this stresses the importance of separating these two concepts when modelling responses.

\section{Mixed prospect}

As indicated before, most people in the mixed prospect part were inequity averse, preferring to obtain the status quo over a treatment involving both gains and losses, with equal expected value of 0 . However, within this group of subjects, arguments were equally divided between Argument 1 and Argument 2. Therefore, there was an equal split between people being inequity averse for reasons of fairness, and people being inequity averse 
because of utility curvature/loss aversion. This once again highlights the need for separating these effects when analysing and interpreting the data.

Table 11. Arguments for mixed prospects

\begin{tabular}{|l|c|c|c|c|c|}
\hline & $\begin{array}{c}\text { Argument 1 } \\
\text { 'Equity' }\end{array}$ & $\begin{array}{c}\text { Argument 2 } \\
\text { 'Utility/loss aversion' }\end{array}$ & $\begin{array}{c}\text { Other } \\
\text { argument }\end{array}$ & No argument & Total \\
\hline No treatment & 165 & 165 & 20 & 34 & 284 \\
\hline Treatment & 74 & 34 & 2 & 23 & 133 \\
\hline Total & 239 & 199 & 22 & 57 & 517 \\
\hline
\end{tabular}

Finally, among the minority choosing the treatment, more subjects indicated Argument 1 as their reason than Argument $2(\mathrm{p}<0.01)$. This suggests that, among the gain seeking subjects, most people give more weight to the group that can gain something, instead of having a convex utility function.

\section{Discussion}

The aims of this research were to extend the measurement of the HRSWF to losses, to estimate a loss aversion index, to test for possible differences between age groups, and to obtain insight into people's reasons for choosing particular options. Knowledge about the HRSWF is important to better understand inequity attitudes with respect to health and how these depend upon framing. Very little research has been done on this topic, with some notable exceptions (Bleichrodt et al., 2005; Turpcu, 2013). This paper has contributed to the literature in that it was the first to measure a loss aversion index in this context, which may, in addition to its frequently reported presence in individual decisions, be of importance in a societal context as well. Our approach was also novel in that we studied QoL improvements and deteriorations instead of longer-lasting QALY profiles.

We observed substantial inequity aversion for gains as well as losses in our experiment and showed it can largely be attributed to both diminishing marginal utility and 'pure equity' concerns (as reflected by equity weighting). The amount of inequity aversion is even larger for losses than for gains, which is largely due to concave utility, as there is no substantial inequity weighting for losses. We also observed the presence of loss aversion and different results for the two versions, indicating clear reference point effects. 
A drawback of our approach is that the estimates of utility curvature and equity weighting are correlated. Consequently, the magnitudes of these coefficients are to some extent disputable. This reinforces the usefulness of complementary argumentative questions, in which most subjects indicated the equity weighting argument to be more important in their decision than the utility curvature argument. However, still a substantial minority of the subjects considered the utility argument to be of greater importance, underscoring the necessity to consider both these concepts in modelling the efficiency-equity trade-off. Furthermore, the finding that equity weighting appears to be more influential than utility curvature does not warrant the latter concept to be irrelevant, as demonstrated by the results of our parametric estimation; it only suggests that equity arguments are apparently more important than diminishing marginal utility arguments in this context.

For losses, to the contrary, there was a clear majority opting for the utility argument to be their main reason to choose the constant allocation. Therefore, these results give another argument to model gains and losses separately, since this is evidence that a separate measurement of equity weighting and utility curvature is not sufficient: a distinct estimation of equity weighting and utility has to be performed for gains and losses, because these concepts turn out to be sign-dependent. This is again supported by the parametric estimates, which showed a significant difference between the equity weights for gains and for losses. More specifically, the answers to the motivational questions predict a larger deviation of the equity weight from 0.5 for gains than for losses, which was indeed confirmed by our estimates.

The comparison of the age groups gave mixed results. There was some indication of subjects being more inequity averse when deciding on behalf of 80 -year old people than when deciding on behalf of younger people, but no significant differences were found for the other comparisons.

Bleichrodt et al. (2005) and Turpcu (2013) measured the entire equity weighting function alongside the utility function, whereas we elicited only one equity weight. The obvious disadvantage was that we had less information about the shape of the equity weighting function. The lack of this information and the correlation between equity weighting and utility curvature highlight the need for a replication of our research that measures these concepts separately by means of two separate tasks, in order to justify more robust conclusions. An advantage, on the other hand, was that the semi-parametric method we applied is much less cognitively demanding, taking only 15 questions to measure utility 
for gains, losses, the equity weight of proportion 0.5 for gains and for losses, and a loss aversion index. This is considerably less than the 120 questions posed in Turpcu (2013).

An explanation for our finding of differences between gains and losses may be that people are sensitive to framing and take the induced starting value as their reference point. However, it may also be that people have their own reference points for different age groups, but mix it up with the starting point, taking some value in-between as their reference point in the experiment. More research with higher sample sizes would be needed to further test this. Finally, our usage of an internet experiment may have lowered reliability of the results. A significant minority of our subjects violated dominance in one or more questions, in that their indifference value was equal to the lowest or highest outcome of the prospect. It would therefore have been better to use personal interviews, but this would be prohibitively costly.

Our results show a lot of mixed subjects, especially if we account for error margins. In order to find out more about these subjects, we performed several additional analyses on them (see Appendix D) ${ }^{8}$. One important conclusion that can be drawn from these analyses is that mixed subjects have a mean Atkinson Index close to 0. This implies that, even though mixed subjects are clearly not inequity neutral, they may be treated as "as if neutral" subjects for societal decision making purposes.

Notwithstanding these limitations, we found some interesting results. First, the finding that diminishing marginal utility and inequity aversion are both relevant contrasts to the results from Bleichrodt et al. (2005) where most inequity aversion seemed to emerge from a convex equity weighting function instead of a concave utility function, and to Turpcu (2013), who found most inequity aversion to be due to concave utility. For gains, the answers to the argumentative questions are more supportive of the conclusions reported by Bleichrodt et al. (2005) than the conclusions from Turpcu (2013). Hence, our results highlight the need for more research into these two concepts of inequity aversion, in order to obtain more robust evidence as to its determinants.

Our findings agree with those of Bleichrodt et al. (2005) and Turpcu (2013) in that we reject the Cobb-Douglas function, i.e. the log-linear utility function, indicating utility is not as concave in our study as in the study of Dolan (1998). Instead, part of the inequity aversion has to be accommodated by the implementation of a separate equity weighting parameter.

\footnotetext{
${ }^{8}$ Appendix D only provides a summary of the results, which are available in full from the corresponding author upon request.
} 
The observation of loss aversion in our societal setting adds to the robustness of the loss aversion phenomenon. Previous research on individual decision making under risk already reported loss aversion to be expandable from the monetary to the health field (Attema et al., 2013; Attema et al., 2015). Moreover, Polman (2012) found evidence for loss aversion using monetary outcomes when people have to decide on behalf of others, although to a smaller extent than when deciding for themselves. We add to this evidence by our findings of loss aversion when deciding on behalf of other people's health. A head-to-head comparison implementing health outcomes in both an individual and a societal environment is recommended for future research in order to compare the amount of loss aversion in these environments.

In conclusion, this paper has proposed a sign-dependent measurement of preferences for equity in health care and found this gain-loss distinction is indeed necessary. In particular, we reported that equity preferences are sign-dependent and can be attributed to both diminishing marginal societal utility and lower weights being given to the worst-off. This was supported by arguments given by the subjects to justify their answers. Finally, loss aversion was shown to be of a similar magnitude when deciding on behalf of others as when deciding for oneself. The results presented in this paper stress the need to perform a distinct estimation of equity weighting and utility for gains and losses. They also indicate that part of the inequity aversion has to be accounted for by implementing a separate equity weighting parameter, because both utility curvature and equity weighting appear to be present in HRSWF elicitations. Finally, age-dependent reference points may be influential in determining preferences for young versus old people, which should be appreciated in both theoretical and practical future studies. 


\section{APPENDIX A. Translation of exemplary questions}

Gains

We are about to ask you questions about what you would do in case you were a policy maker and had to make a choice between two treatments for patients on behalf of the Dutch population. Because these are difficult questions and given that you probably do not face this problem in reality, we will first ask you some simple questions which will hopefully help you in answering this questionnaire.

We will speak about health as a number. If we say that the health of a group of people is 100 , it means that the health of these people is perfect. If we say that their health is equally bad as being dead, then we give their health a value of 0 . Can you indicate how you would rate your own health today on a scale from 0 to 100 ?

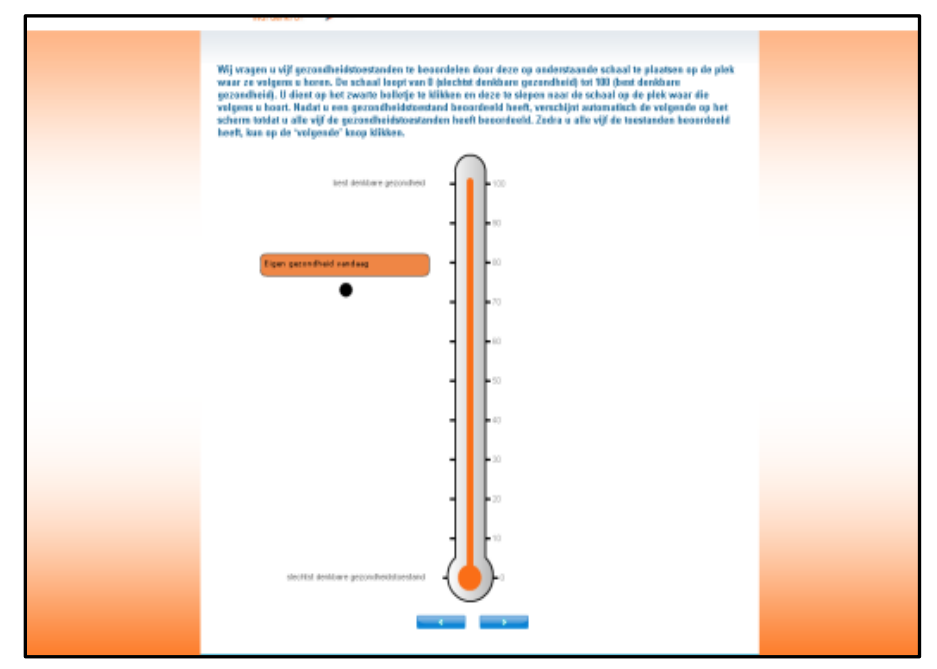

In the following questions, assume that the health of a group of 50-year old people has deteriorated seriously a few years ago. The cause was unknown and doctors could not do anything to improve their health. Their health is, expressed on scale from 0 to 100, only 20 now, while it used to be 100 in the past.

How would you appreciate a health of 20 on a scale from 0 to $100 ?$

-not very bad

-reasonably bad 
-very bad

-extremely bad

Then now the good news. Doctors have found the cause of the problem. Not only that: two medical treatments are available. Both treatments ensure that the condition will completely resolve in one year, so that the health of this group of 50-year old people returns to the old level of 100. However, the treatments differ in the effect they have during the coming year. We will ask you to choose between these two treatments, but first we will better explain the choice problem using a stepwise procedure.

Question 1a.

The effects of Treatment A and B are indicated below. Which treatment would you choose now?

Health of the group 50-year olds without treatment: 20

Treatment A

\begin{tabular}{|c|c|}
\hline & $\begin{array}{l}\text { Health gain } \\
\text { during next year }\end{array}$ \\
\hline $\begin{array}{l}\text { Type I } \\
\text { patients }\end{array}$ & $\begin{array}{c}+11 \\
\text { (from } 20 \text { to } 31 \text { ) }\end{array}$ \\
\hline $\begin{array}{l}\text { Type II } \\
\text { patients }\end{array}$ & $\begin{array}{c}+11 \\
\text { (from } 20 \text { to } 31)\end{array}$ \\
\hline
\end{tabular}

TREATMENT A
Treatment B

\begin{tabular}{|l|c|}
\hline & $\begin{array}{l}\text { Health gain } \\
\text { during next year }\end{array}$ \\
\hline $\begin{array}{l}\text { Type I } \\
\text { patients }\end{array}$ & $\begin{array}{c}+22 \\
\text { (from 20 to 42) }\end{array}$ \\
\hline $\begin{array}{l}\text { Type II } \\
\text { patients }\end{array}$ & $\begin{array}{c}0 \\
\text { (stays 20) }\end{array}$ \\
\hline
\end{tabular}

TREATMENT B

Losses

Practice question 1a.

Imagine a group of 50-year old people has not felt very well the last time and goes to the doctor. The doctor tells them they have a disease that causes their health to deteriorate to 10 during the next year. After this year, the disease is self-limiting and their health will return to the original level of 100. Two treatments are available that can reduce the consequences of the disease. 
Treatment A causes the health of the entire group to drop by 45 from 100 to 55 .

Treatment B causes full recovery in half of the patients (Type I patients): their health will stay at 100. The treatment doesn't work so well in the other half of the patients (Type II patients) and their health immediately drops by 90: from 100 to 10 .

Suppose you are a policy maker. You are not part of the patient group yourself and have to choose between the two treatments on behalf of the Dutch population. It is not possible to determine in advance who is Type I or Type II in Treatment B. This will only be resolved once the treatment has started. Moreover, you cannot choose Treatment B first and then A, or vice versa. You can choose only one treatment.

The initial health of the group and effects of the two treatments are summarized below. Can you indicate whether you would choose Treatment A or Treatment B?

Health of the group of 50-year olds before onset of the disease: 100

Treatment A

\begin{tabular}{|l|c|}
\hline & $\begin{array}{l}\text { Health loss } \\
\text { during next year }\end{array}$ \\
\hline $\begin{array}{l}\text { Type I } \\
\text { patients }\end{array}$ & $\begin{array}{c}-45 \\
\text { (from } 100 \text { to 55) }\end{array}$ \\
\hline $\begin{array}{l}\text { Type II } \\
\text { patients }\end{array}$ & -45 \\
(from 100 to 55)
\end{tabular}

Treatment B

\begin{tabular}{|l|c|}
\hline & $\begin{array}{l}\text { Health loss } \\
\text { during next year }\end{array}$ \\
\hline $\begin{array}{l}\text { Type I } \\
\text { patients }\end{array}$ & $\begin{array}{c}0 \\
\text { (stays 100) }\end{array}$ \\
\hline $\begin{array}{l}\text { Type II } \\
\text { patients }\end{array}$ & -90 \\
(from 100 to 10)
\end{tabular}

\section{TREATMENT A}

\section{TREATMENT B}

\section{Mixed prospect}

Practice question 1a.

In the following questions, assume that the health of a group of 50-year old people has deteriorated seriously a few years ago. The cause was unknown and doctors could not do anything to improve their health. Their health is, expressed on scale from 0 to 100 , only 60 now, while it used to be 100 in the past. 
After one year, the disease is self-limiting and their health will return to the original level of 100. However, doctors have recently developed a treatment that may do something about the disease, but the effects of this treatment are uncertain. In exactly half of the group (Type I patients) the treatment works well. Those people immediately increase to a health level of 100 (a gain of 40). In the other half of the group (Type II patients) the treatment causes a lot of side-effects during the coming year. As a result, the health of those people immediately decreases to 40 (a loss of 30 ).

Suppose you are a policy maker. You are not part of the patient group yourself and have to choose between the two treatments on behalf of the Dutch population. It is not possible to determine in advance who is Type I or Type II in Treatment B. This will only be resolved once the treatment has started. Moreover, you cannot choose Treatment B first and then A, or vice versa. You can choose only one treatment.

The initial health of the group and effects of the two treatments are summarized below. Can you indicate whether you would choose Treatment A or Treatment B?

Health of the group 50-year olds before the disease: 60

No treatment

\begin{tabular}{|l|c|}
\hline & $\begin{array}{l}\text { Health change } \\
\text { during coming } \\
\text { year }\end{array}$ \\
\hline $\begin{array}{l}\text { Type I } \\
\text { patients }\end{array}$ & $\begin{array}{c}0 \\
\text { (stays 60) }\end{array}$ \\
\hline $\begin{array}{l}\text { Type II } \\
\text { patients }\end{array}$ & $\begin{array}{c}0 \\
\text { (stays 60) }\end{array}$ \\
\hline
\end{tabular}

Treatment

\begin{tabular}{|c|c|}
\hline & $\begin{array}{l}\text { Health change } \\
\text { during coming } \\
\text { year }\end{array}$ \\
\hline $\begin{array}{l}\text { Type I } \\
\text { patients }\end{array}$ & $\begin{array}{c}+40 \\
\text { (from } 60 \text { to 100) }\end{array}$ \\
\hline $\begin{array}{l}\text { Type II } \\
\text { patients }\end{array}$ & $\begin{array}{c}-40 \\
\text { (from } 60 \text { to } 20 \text { ) }\end{array}$ \\
\hline
\end{tabular}




\section{APPENDIX B. Questions for explanations}

Questions for arguments for choices

\section{Arguments GAINS}

If subject chose the constant allocation in the first question of $i=x$, we asked the following question:

You indicated you would choose Treatment A. Did your choice have anything to do with one of the following reasons?

1. Both Types of patients will profit in that case. [EQUALITY/CONVEX EQUITY]

2. I consider an improvement from $20 \%$ to $31 \%$ more important than a further improvement from $31 \%$ to $42 \%$. [CONCAVE UTILITY]

Response possibilities

Yes

Namely: Reason 1/2

No

I had another reason, namely:

I did not really have a reason for my choice

If subject chose the unequal allocation in the first question of $\mathrm{i}=\mathrm{x}$, we asked the following question:

You indicated you would choose Treatment B. Did your choice have anything to do with one of the following reasons?

1. The people that won't improve with Treatment B (Type II patients), are still in a respectable health, so I would rather see a part of the group obtaining a substantial health improvement. [CONCAVE EQUITY]

2. I consider an improvement from $20 \%$ to $31 \%$ less valuable than a further improvement from $31 \%$ to $42 \%$. [CONVEX UTILITY]

Response possibilities

Yes

Namely: Reason $1 / 2$ 
No

I had another reason, namely:

I did not really have a reason for my choice

\section{Arguments LOSSES}

If subject chose the equal allocation in the first question of $i=x$, we asked the following question:

You indicated you would choose Treatment A. Did your choice have anything to do with one of the following reasons?

1. It's not fair if the one part of the group loses more health than the other part. [EQUALITY/CONVEX EQUITY]

2. I consider deterioration from $60 \%$ to $55 \%$ as less severe than a further deterioration from $55 \%$ to $49 \%$. [CONCAVE UTILITY]

Response possibilities

Yes

Namely: Reason $1 / 2$

No

I had another reason, namely:

I did not really have a reason for my choice

If subject chose the unequal allocation in the first question of $j=1$, we asked the following question:

You indicated you would choose Treatment B. Did your choice have anything to do with one of the following reasons?

1. Then at least 1 part of the group will keep the same health [CONCAVE EQUITY]

2. I consider deterioration from $60 \%$ to $55 \%$ more severe than a further deterioration from $55 \%$ to $49 \%$. [CONVEX UTILITY]

Response possibilities

Yes

Namely: Reason $1 / 2$ 
No

I had another reason, namely:

I did not really have a reason for my choice

\section{Arguments MIXED PROSPECT}

If subject chose no treatment in the first question, we asked the following question:

You indicated you would not choose the treatment. Did your choice have anything to do with 1 of the following reasons?

1. It's not fair if the one part of the group loses and the other part wins [EQUALITY/CONVEX EQUITY]

2. A gain of 20 is insufficient to compensate for a loss of 20 [CONCAVE UTILITY FOR GAINS/CONVEX UTILITY FOR LOSSES AND/OR LOSS AVERSION]

Response possibilities

Yes

Namely: Reason 1/2

No

I had another reason, namely:

I did not really have a reason for my choice

If subject chose the treatment in the first question, we asked the following question:

You indicated you would choose the treatment. Did your choice have anything to do with 1

of the following reasons?

1. Then at least a part of the group gets a better health [CONCAVE EQUITY]

2. A gain from $60 \%$ to $80 \%$ really makes a difference, while a deterioration from $60 \%$ to $40 \%$ does not make much of a difference [CONVEX UTILITY FOR GAINS/CONCAVE UTILITY FOR LOSSES AND/OR GAIN SEEKING]

Response possibilities

Yes

Namely: Reason 1/2

No

I had another reason, namely:

I did not really have a reason for my choice 


\section{APPENDIX C. Alternative classification of individuals}

Table C1. Classification according to $\bar{q}^{j}$ when including an error margin of $+/-5 \%$ for inequity neutrality (FRP)

\begin{tabular}{|l|l|c|c|c|c|c|}
\hline & Losses & & & & & \\
\hline & $\begin{array}{c}\text { Inequity } \\
\text { averse }\end{array}$ & $\begin{array}{c}\text { Inequity } \\
\text { neutral }\end{array}$ & $\begin{array}{c}\text { Inequity } \\
\text { seeking }\end{array}$ & Mixed & Total \\
\hline Gains & $\begin{array}{l}\text { Inequity } \\
\text { averse }\end{array}$ & 48 & 0 & 4 & 35 & 87 \\
\hline & $\begin{array}{l}\text { Inequity } \\
\text { neutral }\end{array}$ & 0 & 7 & 0 & 1 & 8 \\
\hline & $\begin{array}{l}\text { Inequity } \\
\text { seeking }\end{array}$ & 4 & 1 & 24 & 16 & 45 \\
\hline & Mixed & 37 & 3 & 9 & 75 & 124 \\
\hline & Total & 89 & 11 & 37 & 127 & 264 \\
\hline
\end{tabular}

Table C2. Classification according to $\bar{q}^{j}$ when including an error margin of $+/-5 \%$ for inequity neutrality (URP)

\begin{tabular}{|l|l|c|c|c|c|c|}
\hline & Losses & & & & & \\
\hline & $\begin{array}{c}\text { Inequity } \\
\text { averse }\end{array}$ & $\begin{array}{c}\text { Inequity } \\
\text { neutral }\end{array}$ & $\begin{array}{c}\text { Inequity } \\
\text { seeking }\end{array}$ & Mixed & Total \\
\hline Gains & $\begin{array}{l}\text { Inequity } \\
\text { averse }\end{array}$ & 63 & 3 & 14 & 37 & 117 \\
\hline & $\begin{array}{l}\text { Inequity } \\
\text { neutral }\end{array}$ & 3 & 2 & 3 & 10 & 18 \\
\hline & $\begin{array}{l}\text { Inequity } \\
\text { seeking }\end{array}$ & 1 & 0 & 7 & 5 & 13 \\
\hline & Mixed & 26 & 6 & 7 & 66 & 105 \\
\hline & Total & 93 & 11 & 31 & 118 & 253 \\
\hline
\end{tabular}




\section{APPENDIX D. Additional analyses}

We performed a number of additional tests on the classifications as inequity averse/neutral/seeking/mixed subjects both for gains and for losses. First, we computed the mean Atkinson index (AI) for each subject and compared the according classifications (i.e., averse [seeking, neutral] if $\mathrm{AI}>0[<0,=0])$ to the ordinal classifications that allow for an error margin of $+/-2.5 \%$ (Tables $4 \mathrm{~b}$ and $6 \mathrm{~b}$ ). Ordinal inequity aversion [seeking] in almost all cases corresponded to a positive [negative] AI, and mixed subjects were about equally divided between positive and negative mean AIs.

Second, we computed whether this mean AI was significantly different from 0 , and we found that for $95-100 \%$ of the mixed subjects this was not the case, whereas this percentage was below 40 for inequity averse and seeking subjects. Related to this, we calculated the mean AIs for mixed subjects with $\mathrm{AI}>0$ and mixed subjects with $\mathrm{AI}<0$ separately, and observed that the absolute values of these means were substantially lower than those of the non-mixed subjects.

Third, we computed the mean standard deviations for inequity averse subjects, inequity seeking subjects, mixed subjects with a positive AI and mixed subjects with a negative AI. This gave very similar results, suggesting that mixed subjects were not classified as mixed because of being 'confused' or making more errors (which could be an explanation if their standard deviations were higher than those of non-mixed subjects). 


\section{References}

-Abasolo I, Tsuchiya A. Exploring social welfare functions and violation of monotonicity: an example from inequalities in health. Journal of Health Economics 2004;23; 313-329.

-Abásolo I, Tsuchiya A. Is more health always better for society? Exploring public preferences that violate monotonicity. Theory and Decision 2013;74; 539-563.

-Abdellaoui M, Bleichrodt $\mathrm{H}$, l'Haridon O. A tractable method to measure utility and loss aversion under prospect theory. Journal of Risk and Uncertainty 2008;36; 245-266.

-Andersson F, Lyttkens CH. Preferences for equity in health behind a veil of ignorance. Health Economics 1999;8; 369-378.

-Atkinson AB. On the measurement of inequality. Journal of Economic Theory 1970;2; 244263.

-Attema AE, Brouwer WBF, l'Haridon O. Prospect theory in the health domain: A quantitative assessment. Journal of Health Economics 2013;32; 1057-1065.

-Attema AE, Brouwer WBF, l'Haridon O, Pinto-Prades J. An elicitation of utility for quality of life under prospect theory. Working paper. 2015.

-Bleichrodt H. Health utility indices and equity considerations. Journal of Health Economics $1997 ; 16 ; 65-91$.

-Bleichrodt H, Diecidue E, Quiggin J. Equity weights in the allocation of health care: the rank-dependent QALY model. Journal of Health Economics 2004;23; 157-171.

-Bleichrodt H, Doctor J, Stolk E. A nonparametric elicitation of the equity-efficiency tradeoff in cost-utility analysis. Journal of Health Economics 2005;24; 655-678.

-Bleichrodt H, Miyamoto J. A Characterization of Quality-Adjusted Life-Years Under Cumulative Prospect Theory. Mathematics of Operations Research 2003;28; 181-193.

-Bosworth R, Cameron TA, DeShazo JR. Demand for environmental policies to improve health: Evaluating community-level policy scenarios. Journal of Environmental Economics and Management 2009;57; 293-308.

-Brouwer WBF, van Exel NJA. Expectations regarding length and health related quality of life: Some empirical findings. Social Science \& Medicine 2005;61; 1083-1094.

-Brouwer WBF, van Exel NJA, Stolk EA. Acceptability of less than perfect health states. Social Science \& Medicine 2005;60; 237-246.

-Cuadras-Morató X, Pinto-Prades J, Abellán-Perpiñán J. Equity considerations in health care: the relevance of claims. Health Economics 2001;10; 187-205. 
-Dolan P. The measurement of individual utility and social welfare. Journal of Health Economics 1998; 17; 39-52.

-Dolan P, Cookson R. A qualitative study of the extent to which health gain matters when choosing between groups of patients. Health Policy 2000;51; 19-30.

-Dolan P, Robinson A. The measurement of preferences over the distribution of benefits: The importance of the reference point. European Economic Review 2001;45; 1697-1709.

-Dolan P, Shaw R, Tsuchiya A, Williams A. QALY maximisation and people's preferences: a methodological review of the literature. Health Economics 2005;14; 197-208.

-Dolan P, Tsuchiya A. Determining the parameters in a social welfare function using stated preference data: an application to health. Applied Economics 2011;43; 2241-2250.

-Etchart-Vincent N, l'Haridon O. Monetary incentives in the loss domain and behavior toward risk: An experimental comparison of three reward schemes including real losses. Journal of Risk and Uncertainty 2011;42; 61-83.

-Gächter S, Johnson E, Herrmann A. Individual-level loss aversion in riskless and risky choices. 2007. CeDEx Discussion Paper 2007-02.

-Johannesson M, Gerdtham U. A note on the estimation of the equity-efficiency trade-off for QALYs. Journal of Health Economics 1996;15; 359-368.

-Johannesson M, Johansson P. Is the valuation of a QALY gained independent of age? Some empirical evidence. Journal of Health Economics 1997;16; 589-599.

-Kahneman D, Tversky A. Prospect Theory: An Analysis of Decision under Risk. Econometrica 1979;47; 263-291.

-Lancsar E, Wildman J, Donaldson C, Ryan M, Baker R. Deriving distributional weights for QALYs through discrete choice experiments. Journal of Health Economics 2011;30; 466478.

-Li Z, Rohde KIM, Wakker PP. Improving one's choices by putting oneself in others' shoes - an experimental analysis. Working paper. 2015.

http://people.few.eur.nl/wakker/pdf/choicepredict.pdf.

-Lindholm L, Rosén M. On the measurement of the nation's equity adjusted health. Health Economics 1998;7; 621-628.

-Nord E, Pinto JL, Richardson J, Menzel P, Ubel P. Incorporating societal concerns for fairness in numerical valuations of health programmes. Health Economics 1999;8; 25-39.

-Péntek M, Brodszky V, Gulácsi ÁL, Hajdú O, van Exel J, Brouwer W, Gulácsi L. Subjective expectations regarding length and health-related quality of life in Hungary: results from an empirical investigation. Health Expectations 2012; n/a-n/a. 
-Polman E. Self-other decision making and loss aversion. Organizational Behavior and Human Decision Processes 2012;119; 141-150.

-Schwappach DLB, Strasmann TJ. "Quick and dirty numbers"?: The reliability of a statedpreference technique for the measurement of preferences for resource allocation. Journal of Health Economics 2006;25; 432-448.

-Shalev J. Loss Aversion and Bargaining. Theory and Decision 2002;52; 201-232.

-Skedgel CD, Wailoo AJ, Akehurst RL. Choosing vs. allocating: discrete choice experiments and constant-sum paired comparisons for the elicitation of societal preferences. Health Expectations 2013; n/a-n/a.

-Szende A, Janssen B, Cabases J. Self-Reported Population Health: An International Perspective based on EQ-5D. Springer; 2014.

-Tom SM, Fox CR, Trepel C, Poldrack RA. The Neural Basis of Loss Aversion in DecisionMaking Under Risk. Science 2007;315; 515-518.

-Turpcu A. Essays on the equitable distribution of healthcare,Proquest Umi Dissertation Publishing; 2011.

-Tversky A, Kahneman D. Advances in Prospect Theory: Cumulative Representation of Uncertainty. Journal of Risk and Uncertainty 1992;5; 297-323.

-van Osch SMC, Stiggelbout AM. The construction of standard gamble utilities. Health Economics 2008; 17; 31-40.

-van Osch SMC, van den Hout WB, Stiggelbout AM. Exploring the Reference Point in Prospect Theory: Gambles for Length of Life. Medical Decision Making 2006;26; 338-346.

-Vieider FM, Chmura T, Martinsson P. Risk attitudes, development, and growth macroeconomic evidence from experiments in 30 countries. Working paper. 2015. http://www.ferdinandvieider.com/risk development growth.pdf.

-Wagstaff A. QALYs and the equity-efficiency trade-off. Journal of Health Economics $1991 ; 10 ; 21-41$.

-Wakker PP. Prospect theory: For risk and ambiguity, Cambridge: Cambridge University Press; 2010.

-Wakker P, Deneffe D. Eliciting von Neumann-Morgenstern Utilities When Probabilities Are Distorted or Unknown. Management Science 1996;42; 1131-1150.

-Williams A. Intergenerational Equity: An Exploration of the 'Fair Innings' Argument. Health Economics 1997;6; 117-132. 